\title{
The rules of insanity: commentary on: Psychopathic disorder: a category mistake?
}

\author{
Carl Elliott University of Otago, Dunedin, New Zealand
}

\section{Author's abstract \\ This paper addresses Colin Holmes's suggestion that the psychopathic disorder is best regarded not as a psychiatric concept, but as an ethical one. The paper argues that the concept of psychopathy, like many other concepts, can span both psychiatry and ethics, and that it is not clear what removing it from the realm of psychiatry would entail. Also, the question of whether the concept of psychopathy is useful for psychiatrists must be separated from the question of whether psychopaths should be exonerated from the moral and legal responsibility for their actions.}

It is ironic that psychiatry, which expends so much effort on the patient who feels guilty when most of us think he should not, should find itself occupied with the psychopath, who feels no guilt when most of us think that he should. And as Colin Holmes points out, the absence of guilt and other moral emotions is one of the most consistent and longstanding features of the psychopathic disorder and its historical predecessors (1). But ironic does not mean misguided, as Holmes implies of psychiatrists when he suggests that they have made a category mistake in attending to the psychopathic disorder. Holmes suggests that psychopathy is better regarded not as a psychiatric category, but as an ethical one. Whether such a suggestion is helpful, however, will depend on its content, and the content of Holmes's suggestion is by no means clear.

I take it that by consigning the concept of psychopathy to the 'labyrinthine procrastinations of moral and legal philosophers', a presumably harmless oblivion, Holmes does not mean that psychopaths should not be the proper object of psychiatric research, since much of his impressive bibliography consists of the fruits of such research. I also take it that Holmes means to go beyond the claim that the psychopathic disorder is not an illness, a claim for which there is much to be said, but for which much has already been said elsewhere, at much length and about a much wider scope of mental disorders than merely psychopathy.

\section{Key words}

Insanity; psychopathy; responsibility; mental illness; psychiatry.
Rather, by suggesting that psychopath is an ethical category, and not a psychiatric one, I take Holmes to be making a more interesting and more provocative point: that we should cease thinking of psychopathy as a category of psychiatric diagnosis, and think of it instead as a category of moral evaluation.

What Holmes does not adequately address is the question why we must think of the concept of psychopathy as either psychiatric or ethical, and not as both. Many other psychiatric diagnoses have evaluative connotations - think of the paedophile, or the substance abuser - yet we are usually not inclined to banish these concepts from the psychiatric domain. Ethics is not a sphere removed from all others, and ethical concepts pervade the vocabulary of most areas of our lives. Merely to note that a psychiatric concept has evaluative connotations, or that it is of ethical interest, is no reason to say that it should be outside the scope of psychiatry.

Holmes may be suggesting that given the nature of psychopathy, it is a term which is less similar to diagnostic terms such as 'schizophrenic', 'obsessivecompulsive' or 'manic-depressive' than it is to moral terms such as 'cruel', 'courageous', or 'evil'. Given the definition of psychopathy for which Holmes argues, an absence of conscience, 'psychopathic' would fit comfortably along evaluative terms such as 'remorseless' or 'cold-hearted'. And psychopathy by almost any definition differs substantially from many other medical conditions, even psychiatric ones: its victims are not distressed by it; its pathophysiology is unknown; it is diagnosed entirely by behavioural criteria; and attempts at treatment meet with dismal lack of success.

However, it should be remembered, first, that none of the above characteristics is unique to the psychopathic disorder (they will all apply, for example, to Alzheimer's Disease in its late stages), and second, that the definition of psychopathy for which Holmes argues, a lack of conscience, is not one which is commonly used by psychiatrists. Of course, part of the reason that the diagnosis is so controversial is the confusion over what exactly the definition should be, but even those authors whom Holmes cites approvingly, such as Cleckley, mark out a constellation of psychopathic characteristics other than an absence 
of conscience, and which cannot be easily explained as subsets of an absence of conscience. The most consistently described of these seem to be the psychopath's characteristic imprudence and poor judgement.

In fact, it is precisely these characteristics which make the psychopathic disorder a useful term for psychiatry. Whatever the definition of the psychopath, it is clear that many psychopaths frequently run afoul of the law, and that the criminal justice system is no more successful in dealing with the psychopath than is psychiatry. Cleckley speaks bluntly on this point: 'It is my opinion that no punishment is likely to make the psychopath change his ways' (2). The psychopath's persistent legal breaches, his antisocial behaviour and the distress that he causes his family ensure that he will continue to come to the attention of psychiatrists, and the diagnosis of psychopathy provides a means by which to designate what is, if not an illness, at least a recognisable set of behavioural characteristics.

I suspect that Holmes's worries about the concept of psychopathy, like the worries of many others, stem from a conviction that it excuses from moral and legal accountability offenders who ought not to be excused. Holmes argues that the diagnosis of psychopathy is at odds with commonsense notions of moral responsibility and justice, as well as with the way society ascribes illness, and he suggests, plausibly, that psychiatrists have no special expertise on questions of moral and legal responsibility. However, whether or not the psychopath ought to be held responsible for his wrongs is a question quite separate from that of whether or not the concept is useful for other purposes.

Much jurisprudential energy is spent on demarking categories and deciding what rules should apply to those categories. It is a source of longstanding debate what mental disorders, illnesses, diseases, depravities and abnormalities of mind should be admitted as pleas of insanity, and thus as an excusing condition; and it is another debate whether insanity is itself an excusing condition, or instead a species of another excusing condition, such as ignorance or compulsion. But regardless of what should be categorised as mental illness or insanity, it should be plain that many (perhaps most) of the patients that psychiatrists treat can be justifiably held morally and legally responsible for many of their actions. Whether their disorder is an excuse will depend on the action and the disorder. A person with paranoid delusions who assaults the postman, thinking he is acting in self-defence, is a good candidate for exoneration, but a compulsive handwasher who cheats at poker is not. Thus the mere fact that psychiatrists use the concept of psychopathy diagnostically does not mean that psychopaths should be exonerated for their misdeeds.

In the end Holmes's essay raises more questions than it answers, and hence it may, ironically, stimulate interest in the concept of psychopathy rather than dampen it. How are we to understand the 'absence of conscience' which Holmes takes to be the psychopath's defining characteristic? As a defect in his ability to $\underset{\vec{f}}{\vec{F}}$ reason morally? As an emotional deficiency, perhaps $\overrightarrow{0}$ specific to moral sentiments such as empathy, guilt and $\frac{}{\sigma}$ remorse? Or simply as a motivational void? What are we to make of the characteristics which other writers $\mathbb{D}$ attribute to the psychopath, such as imprudence, or the inability to form emotional attachments? Is yet ${ }^{\infty}$ another concept necessary to take account of them? $\vec{\circ}$

The fact that the concept of psychopathy has lasted $\overrightarrow{\vec{\omega}}$ as long as it has suggests that it will not be done away ${ }_{\sigma}$ with easily. Nor should it be. Despite the chance that

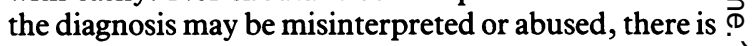
something intriguing about the psychopath - not only $\vec{v}$ the way that he can commit a seemingly endless string iv of offences without guilt, but his often astonishingly $\underset{\infty}{\infty}$ poor judgement, his failure to learn from experience, 음 and in the case of the primary psychopath, the spectacular behaviour that occasionally results. The $\stackrel{c}{\subseteq}$ psychopath's behaviour is at once both understandable and inscrutable; we might find his shameless risk- $\vec{\bullet}$ taking vaguely enviable, an exaggeration of impulses $\stackrel{\bullet}{\longrightarrow}$ which we share, yet remain baffled at his selfdestructiveness, the way he repeatedly and carelessly pursues courses of action which run directly counter to his own interests, and which any child could see would lead to disaster. We may be unwilling to call the psychopath ill, but neither can we say with much $\stackrel{\Phi}{\varrho}$ confidence that he is mentally sound. He seems a $\vec{\circ}$ hollow man, unmoved by the aims and emotions of 3 ordinary humans, careless of even his own well-being. Who could fail to be fascinated by case histories of, say, a figure who would attempt to disrobe and have sexual intercourse with an unwilling partner on a crowded ballroom dance floor, or travel about on a whim for $\frac{5}{3}$ several weeks impersonating a travelling evangelist, or defecate in the aisle of the church during a family funeral (3)?

Murky concepts attract simple explanations, and for 옥 this reason Holmes's account carries some appeal. It $\rightarrow$ frames the concept of psychopathy in deceptively simple terms, and in so doing removes it from the $N$ medical realm. But Holmes's account does not do justice to the actual phenomenon of psychopathy, and 0 even if it did, it has many hidden complexities of its $\omega$ own.

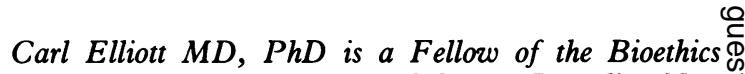
Research Centre, University of Otago, Dunedin, New? Zealand.

\section{References}

(1) Holmes C. Psychopathic disorder: a category mistake? Fournal of medical ethics 1991, 17: 77-85.

(2) Cleckley H. The mask of sanity. St Louis: C V Mosby, 1976: 346.

(3) See reference (2): 155, 153, 139. 